\title{
Agile Methodology to Performance Measure and Identification of Impact Factors in the Labour Productivity of Industrial Workers
}

\author{
Diego Calvetti N. ${ }^{1}$, Miguel Luiz Ribeiro Ferreira ${ }^{2}$ \\ ${ }^{1}$ Graduate Program of Industrial Construction, Federal Fluminense University, Niterói, \\ Brazil; Department of Civil Engineering, Faculty of Engineering University of Porto, \\ Porto, Portugal (diego.calvetti@fe.up.pt) ORCID 0000-0001-9893-0377; ${ }^{2}$ Graduate \\ Program of Industrial Construction, Federal Fluminense University, Niterói, Brazil \\ (miguelluiz@id.uff.br) ORCID 0000-0002-8576-5672
}

\begin{abstract}
The objective of this work is to adapt and test an agile methodology based on human observation that waives the data collection based on the timing of time in activity. Aiming to evaluate the productivity and non-productivity of workers in a factory during the pipe welding process for use in the construction of industrial plants. Through human observation the data was gathered by registering punctually the activities of the welders during a week. The results obtained by the Monte Carlo simulation were validated by comparing the results obtained by the probability and statistically analysis of the complete sample. After the simulation validation the Sensibility Analysis test was conducted in order to evaluate the variables of higher impact in the performance of the welders. The average of Labour Rating Factor and Idleness Rating Factor obtained by Monte Carlo simulation were respectively, 0.5529 and 0.4549 and by the sampling chart Labour Rating Factor 0.5552 and Idleness Rating Factor 0.4448. The methodology identified 9(nine) actions in the productive state, where the welding activity presents the greatest impact on the output of the mean of the Labour Rating Factor. In addition, 8(eight) actions were considered non-productive, where displacements and human conditions activities have the greatest impact on the Idleness Rating Factor. Furthermore, the results were compared with the work of other Authors. The research results shows the feasibility for industry to use this proposal of an agile methodology for evaluating the workforce performance, spending less resource compared with traditional ones.
\end{abstract}

Author Keywords. Monte Carlo Method, Sensibility Analysis, Labour Productivity, Workers, Continuous Improvement

Type: Research Article

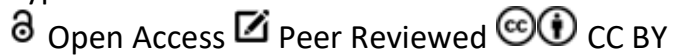

\section{Introduction}

The performance evaluation and identification of factors that affect productivity in the heavy construction industry area is based mainly in the post-analysis of historical data. Thus, not allowing the application of corrective actions during the execution of the project activities. In the same way, the work productivity is fundamental information in order to estimate and monitor the deadlines of a construction project. Being that, nowadays, in construction industry its estimative is based in productivity data of publications or in the experience of one or more individuals. In this sense, Song and AbouRizk (2008) affirm that, although the historical data of projects maintain important 
information about productivity, the lack of a consistent measurement system and the low quality of the aforementioned data might prevent a reliable analysis of it.

The studies based in referential and historical data, as well as in surveys are widely applied in the construction industry. Several post-analytic data approaches are applied to obtain the metrics and also to identify the impact factors facing productivity and unproductiveness, such as: Baseline productivity measurements by Thomas and Završki (1999); Metrics for benchmarking performance by Allmon et al. (2000), Park, Stephen, and Richard (2005), Abdel-Razek, Abd Elshakour M, and Abdel-Hamid (2007), Enshassi et al. (2007), and Doloi et al. (2012). The monitoring and knowledge of the factors that impact productivity are fundamental elements in the management of enterprises. On the other hand, according to Nasirzadeh and Nojedehi (2013) the work productivity is affected by several factors, directly and indirectly, being the dynamical system extremely apt to model this interaction. According to Mojahed and Aghazadeh (2008), in the construction industry context, productivity is directly related to the performance achieved of each labour activity done in a worksite. However, it is verified that while the transformation industry has benefited through production management techniques of proven efficiency, the construction industry remains out dated due to insufficient investigation in the productivity area. This situation is worrying because construction companies need to continuously improve productivity performance in order for them to maintain their competitiveness. In this sense, Navon (2005), and Pradhan, Akinci, and Haas (2011), agree that the frequent monitoring of productivity and the analysis of the activities being done, help evaluate a project performance and allow the identification of improvement opportunities.

This is due to the complexity of the work, as well as the high degree of costing required, variable processing time and high degree of work intensity. Christian and Hachey (1995) affirm that there are several factors that influence productivity in the construction industry, including those that entail variations in production rates, which are particularly difficult to control. However, according to these authors, there are other factors which may be easily identified and upon which, it is possible to act in order to obtain significant improvements on production rates. In the same way, according to Christian and Hachey (1995), the focus of attention in production management must be directed on the sources and causes of delays. Still according to them, the unproductive time division in two factors, the time stopped and time waiting is very important in order to direct the management attention to the causes on unproductive time. Czumanski and Lödding (2016) emphasize the need for industries to continually improve their processes, thus requiring a rapid analysis of the productive state, thus providing a rapid productivity management response. In this way, the present study seeks to test a technique for an agile diagnosis of labour productivity, measuring the performance level of workers and identifying the factors of productivity impact and thus, also measuring the main logistical problems in the work process.

\section{Background}

According to Adrian (2004), one of the ways to classify the workforce is related to the work type it does, e.g.: carpenter, mason or welder. Other classification possibility concerns with the productive estate, productive or non-productive, that a work present during the realization of certain activity. According to Adrian (2004), the evaluation of the productive state depends on the observer's viewpoint. The author defines that a 
worker's action classified as productive is directly related to the main or auxiliary tasks that are being observed. In the case of welders, which are the focus of this work, welding would be classified as a productive action and activities such as, changing the torch diffusor and regulating the welding machine, would be classified as auxiliary. On the other hand, when a worker isn't doing anything or doing strange activities to the productive process, the action is classified as non-productive, e.g.: chatting with colleagues, drinking water and in unnecessary displacement.

Punctual random observations and its classification as to the productive and nonproductive state may be performed in multiple teams, in a specific worker category and even on a single worker (Adrian 2004). The Adrian (2004) model to determine the Labour Rating Factor (LRF) is based in the synthesis of human observations randomly performed, according to its classification as productive in relation to the total number of observations performed. In an analogous way, the Idleness Rating Factor (IRF) expresses the quantity of observations registered of the non-productive activities in relation to the total, according to the following Equation 1 and Equation 2:

$$
\begin{gathered}
L R F=\frac{\text { Number of observations of productive state }}{\text { Total number of observations }} \\
I R F=\frac{\text { Number of observations of nonproductive state }}{\text { Total number of observations }}
\end{gathered}
$$

It is important to mention that the method is based on the number of observations performed, not being necessary the timing or any other verification. It is noted that the increase in the number of observations registered is directly related to the increase of the confidence limit and the decrease of the modelling limit error. Still, regardless of the sample size, an uncertainty will always occur in the obtained result. In this sense, aiming to quantify the modelling uncertainty rate, three statistical concepts are used:

\begin{tabular}{|c|c|c|c|c|c|c|c|c|c|c|c|}
\hline \multicolumn{6}{|c|}{$\begin{array}{l}\text { Sample sizes required for } 95 \% \text { confidence } \\
\text { limits }\end{array}$} & \multicolumn{6}{|c|}{ Sample sizes required for $90 \%$ confidence limits } \\
\hline \multirow{2}{*}{$\begin{array}{l}\text { Category } \\
\text { proportion } \\
(\%)\end{array}$} & \multicolumn{5}{|c|}{ Limits of Error ( \%) } & \multirow{2}{*}{$\begin{array}{l}\text { Category } \\
\text { proportion } \\
(\%)\end{array}$} & \multicolumn{5}{|c|}{ Limits of Error ( \%) } \\
\hline & 1 & 3 & 5 & 7 & 10 & & 1 & 3 & 5 & 7 & 10 \\
\hline 50 & 9600 & 1067 & 384 & 196 & 96 & 50 & 6763 & 751 & 270 & 138 & 68 \\
\hline $40 / 60$ & 9216 & 1024 & 369 & 188 & 92 & $40 / 60$ & 6492 & 721 & 260 & 132 & 65 \\
\hline $30 / 70$ & 8064 & 896 & 323 & 165 & 81 & $30 / 70$ & 5681 & 631 & 227 & 116 & 57 \\
\hline $20 / 80$ & 6144 & 683 & 246 & 125 & 61 & $20 / 80$ & 4328 & 481 & 173 & 88 & 43 \\
\hline $10 / 90$ & 3456 & 384 & 138 & 71 & 35 & $10 / 90$ & 2435 & 271 & 97 & 50 & 24 \\
\hline $1 / 99$ & 380 & 42 & 15 & 8 & 4 & $1 / 99$ & 268 & 30 & 11 & 5 & 3 \\
\hline
\end{tabular}
confidence limit, limit offer and category proportion (Adrian 2004), see Table 1.

Table 1: confidence limits (Adrian 2014)

The confidence limit indicates the estimate reliability, in a way that it represents the parameter to validate the collected sample, being arbitrarily selected from within the pre-established statistical tabulations. The category proportion refers to the characteristic of the measured sample, in a way that, it represents the relative frequency identified within a determined parameter being analysed, e.g. the number of observations identified as productive state proportionally facing the size of the total sample. The error limit is the superior and inferior parameter of precision of the average value determined in the modelling (Adrian 2004). 
Monte Carlo method comprises the generation of virtual data, pseudo-random numbers, from a sample of real data and may be used in different types of studies. Considering this perspective, Chan and Malmborg (2013) carried out a research to evaluate the efficacy of Monte Carlo simulation in conjunction with heuristics in solving large layout problems. The results obtained allowed authors to conclude for the applicability of the modelling processes based in Monte Carlo simulation. Yi and Chan (2013) used Monte Carlo simulation to optimize scheduling of downtime and safety activities for workers at a construction site to improve productivity. Choudhry et al. (2014) developed a work to evaluate the effects of cost and time risks in the construction of a bridge. Gelisen and Griffis (2014) have developed of a model to automatically update the performance indicators of a project, estimating the impact of events and activities on labour productivity. Constâncio, Ferreira, and Freire (2009), Martins, Ferreira, and Saraiva (2011), and Martins et al. (2012), applied a methodology based on Monte Carlo simulation to estimate the productivity of welding of butt joints in carbon steel pipes, based on small samples.

Sensitivity analysis is used for a wide range of purposes. Jovanović (1999), in an article on the evaluation of investment projects, states that through this tool it is possible to detect the impact of possible variations of a dependent variable, alone, on the main one. According to Schuyler (2001), the sensitivity analysis allows to distinguish the relative importance of the elements of a model. The author argues that this methodology aims to identify fundamental variables of a model, prioritizing them and providing more precise information about their behaviour. Raftery (2003), in his book on risk analysis in project management, states that the sensitivity analysis measures the effect on an output of a model of certain specifics variations of their input variables parameters. Flanagan and Norman (1993), consider that sensitivity analysis allows to evaluate the variables that present the major risks in construction projects. Alvanchi, Lee, and AbouRizk (2012), applied sensitivity analysis and Monte Carlo simulation by studying the effects on productivity of changes occurring throughout the day, overtime and worker resistance of work conditions. Lobato (2015), applied a Tornado Diagram, which is one of the main tools used in Sensitivity Analysis, in a study to evaluate the impact of all activities involved in a welding procedure.

\section{Experimental Procedure}

The activities performed during the evaluation period consisted of the welding of low carbon alloy steel pipes by Tungsten Inert Gas (TIG) and Flux-cored arc welding (FCAW) methods. Because it is a pipe-shop, the processes take place in a production line. The study was carried out by observing ten welders during their usual activities in a regular working day. Among qualified welders in accordance with the norms of regulation used in the Brazilian industry. The data collection procedure had the objective of detecting the actions developed by the welders within their working day, so that the best characterization of each action was sought, aiming at its later classification within a two states determined by Adrian (2004), which are: Productive - worker performing activity directly from the process, or some auxiliary activity; Nonproductive - worker not performing activities, or in activities considered idle. For data entry, a spreadsheet was elaborated to make the annotations based on the observation of the ten welders in analysis, in the format of a sampling chart. Aiming to facilitate the identification of employees, signs were implemented with number and colour as coded in the helmets and welding masks of each welder. The resources used to collect and store the data 
through the application of the sampling chart method are listed below: Two observers; Two sets containing model sheets printed from the sampling chart, clipboard and pen; Forty-four self-adhesive stickers, previously modelled with employee identification, implemented on helmets and welding masks; Two notebooks with MS Excel software for tabulation and data analysis. The observations occurred between 30 June 2015 and 06 August 2015, and, during this period, 3577 records of field observations were collected regarding the productive status of the ten welders under analysis. Among which, 1986 were classified as productive and 1951 as non-productive.

To evaluate the behaviour of the Labour Rating Factor and the Idleness Rating Factor of the Labour Force, the Monte Carlo Simulation technique was used with the software @risk 7.5 from the Palisade Corporation, through which the Probability Distribution Function (PDF), from which it was possible to evaluate the behaviour of the Rating Factors of the workforce.

The Determination of Rating Factors considers the population of all events observed. The Probability Distribution Function curves obtained correspond to the sum of the functions, which represent the behaviour of each of the events that are characterized as Productive or Non-Productive. In this case, a specific Probability Distribution Function represents the behaviour of each event considered. The database used in the simulations corresponds to the data collected from the ten welders. The simulation process basically follows the steps below: Grouping the data collected in the field in MS Excel worksheets according to the characteristics of the actions with productive or nonproductive; Determination of the appropriate Probability Distribution Function using the Akaike method (AIC) as the adhesion test; Monte Carlo data simulation with 5000 iterations; Verification of the sufficiency of the number of iterations, through the convergence analysis provided by the computational program; Development and determination of statistical parameters for analysis; Development and determination of the cumulative and density Probability Distribution Function curve and calculation of the statistical parameters for analysis.

In order to validate the Monte Carlo modelling, the work-sampling model was applied by Adrian (2004), and the results of the Probability Distribution Function curves obtained according to the Monte Carlo simulation are compared. Thus, was comparing the average of the values of these curves, their respective standard deviations and coefficients of variation with the determined values and their respective error limits, obtained by the use of the sampling chart. Also, according to Adrian (2004), the determination Labour Rating Factor consists of the ratio between the sum of the number of records of actions considered as productive activity by the total of the observations made. Analogously, the calculation of the Idleness Rating Factor is based on dividing the sum of the records of the observations of the activities defined as nonproductive and total of the observations made. Adrian (2004) presents an example sampling chart, as previously seen in Table 1, which has application in studies in the construction industry. In this table, based on the sample size, the 0.9500 or 0.9000 confidence limit, the proportion category, and the perceptual error of the result against the sample size are delineated. In this work, the 0.9500 confidence limit and 0.5000 ratio category were adopted to establish the expected error limits.

To determine the impact of each event on the Labour Rating Factor and Idleness Rating Factor, after data modelling via Monte Carlo the sensitivity analysis is developed by means of the tornado diagram developed by the mean deviation, which is a tool 
available in the software @Risk 7.5 from Palisade Corporation. It is worth noting that for the adoption of this technique, the Probability Distribution Function curves considered are those where the model representing the behaviour of the Productive and Nonproductive states corresponds to the sum of the Functions curves of all the events that characterize them. In this case, it is possible to determine which events have the greatest impact on the average output of the Labour Rating Factor and Idleness Rating Factor. Also, a test is performed to evaluate the minimum and maximum impacts of each variable on the mean of the main variable under analysis based on the standard deviation found for both the Labour Rating Factor and the Idleness Rating Factor. However, the sensitivity analysis indicates which variables will have the greatest impact on the main variable under analysis and which should be prioritized for the application of improvement actions in production.

\section{Results and Discussion}

\subsection{Labour and idleness rating factors by Monte Carlo analysis}

The data collected on the production status of the workforce were catalogued according to the identified actions of the welders under evaluation during the study, totalizing 3577 observations. Such actions are categorized as Productive or Nonproductive. Thus, Table 2 presents the number of total points, which correspond to the events in which the welders were involved at the moment of data collection, recorded through human observation. 


\begin{tabular}{|c|c|c|c|c|c|c|c|c|c|c|c|c|}
\hline \multirow{2}{*}{$\begin{array}{l}\text { Productive } \\
\text { State }\end{array}$} & \multirow[b]{2}{*}{ ID } & \multirow[b]{2}{*}{ Identified Actions } & \multicolumn{10}{|c|}{ Number of observations } \\
\hline & & & $\begin{array}{c}\text { Welder } \\
1 \\
\end{array}$ & $\begin{array}{c}\text { Welder } \\
2 \\
\end{array}$ & $\begin{array}{c}\text { Welder } \\
\mathbf{3} \\
\end{array}$ & $\begin{array}{c}\text { Welder } \\
4\end{array}$ & $\begin{array}{c}\text { Welder } \\
5 \\
\end{array}$ & $\begin{array}{c}\text { Welder } \\
6\end{array}$ & $\begin{array}{c}\text { Welder } \\
7\end{array}$ & $\begin{array}{c}\text { Welder } \\
8 \\
\end{array}$ & $\begin{array}{c}\text { Welder } \\
9\end{array}$ & $\begin{array}{c}\text { Welder } \\
10\end{array}$ \\
\hline \multirow{9}{*}{ Productive } & 1 & Welding & 122 & 131 & 122 & 116 & 102 & 103 & 105 & 110 & 86 & 73 \\
\hline & 2 & $\begin{array}{l}\text { Collecting cables, removing PPE's and storing } \\
\text { equipments }\end{array}$ & 19 & 17 & 18 & 17 & 11 & 18 & 16 & 18 & 17 & 13 \\
\hline & 3 & Cleaning the work area & 1 & 2 & 0 & 0 & 0 & 1 & 0 & 1 & 2 & 0 \\
\hline & 4 & Closing spool openings to purge & 0 & 1 & 10 & 0 & 8 & 4 & 0 & 0 & 1 & 0 \\
\hline & 5 & $\begin{array}{l}\text { Making the change of diffuser and/or torch nozzle } \\
\text { and/or sharpening the tungsten }\end{array}$ & 15 & 3 & 11 & 12 & 10 & 8 & 11 & 0 & 5 & 0 \\
\hline & 6 & Sanding & 41 & 48 & 39 & 53 & 35 & 42 & 20 & 50 & 66 & 36 \\
\hline & 7 & $\begin{array}{l}\text { Evaluating the task (position, questions with } \\
\text { supervisor) }\end{array}$ & 0 & 9 & 19 & 12 & 10 & 8 & 15 & 20 & 9 & 12 \\
\hline & 8 & Spool Adjustments and Alignments & 10 & 2 & 4 & 15 & 17 & 4 & 1 & 0 & 17 & 0 \\
\hline & 9 & Recording the Signet & 2 & 7 & 8 & 1 & 5 & 0 & 0 & 3 & 4 & 2 \\
\hline \multirow{8}{*}{ Nonproductive } & 10 & Displacements & 58 & 66 & 81 & 57 & 54 & 108 & 92 & 32 & 79 & 39 \\
\hline & 11 & No joints released to start welding & 0 & 0 & 0 & 0 & 0 & 0 & 0 & 53 & 0 & 0 \\
\hline & 12 & $\begin{array}{l}\text { Interruption of activities due to the movement of } \\
\text { loads near the workbench }\end{array}$ & 1 & 2 & 1 & 0 & 0 & 2 & 1 & 3 & 2 & 0 \\
\hline & 13 & Waiting for crane availability & 47 & 60 & 6 & 2 & 17 & 34 & 0 & 28 & 38 & 7 \\
\hline & 14 & $\begin{array}{l}\text { Awaiting the arrival of the inspector to the joint } \\
\text { release }\end{array}$ & 5 & 9 & 2 & 7 & 2 & 6 & 5 & 15 & 22 & 8 \\
\hline & 15 & $\begin{array}{c}\text { Human Conditions - Interaction with colleagues, } \\
\text { cool the body, drink water and go to the } \\
\text { bathroom }\end{array}$ & 24 & 12 & 44 & 51 & 43 & 32 & 24 & 37 & 17 & 53 \\
\hline & 16 & Security and Management Meetings & 16 & 16 & 18 & 13 & 11 & 15 & 19 & 15 & 17 & 12 \\
\hline & 17 & No welding machine or defective machine & 14 & 0 & 0 & 34 & 0 & 0 & 0 & 3 & 0 & 0 \\
\hline
\end{tabular}

Table 2: $\mathrm{K}$ clustering - non-hierarchical classification 
To obtain the curve that represents the function that expresses the impact of each activity identified in Table 2, the Monte Carlo simulation was performed. A positive evaluation of the convergence analysis was sought, thus, the simulation was performed with 5000 iterations, and the appropriate Probability Distribution Function was determined through the Akaike adhesion test. Thus, if the variability of each function was reduced, it was possible to reduce the final dispersion of the Rating Factors. The Labour Rating Factor function obtained through Monte Carlo simulation, which is the sum of the functions related to the Productive category according to Equation 3 presented, gave rise to the Density Curve presented in Figure 1a. The average Probability Distribution Function result is 0.5529 with standard deviation of 0.0525 , maximum of 0.7942 , minimum of 0.3262 and coefficient of variation of 0.0950 .

At where:

$$
\mathrm{LRF}=\frac{\sum \text { action } 1}{\sum \text { actions }}+\frac{\sum \text { action } 2}{\sum \text { actions }}+\frac{\sum \text { action } 3}{\sum \text { actions }}+\frac{\sum \text { action } 4}{\sum \text { actions }}+\frac{\sum \text { action } 5}{\sum \text { actions }}+\frac{\sum \text { action } 6}{\sum \text { actions }}+\frac{\sum \text { action } 7}{\sum \text { actions }}+\frac{\sum \text { action } 8}{\sum \text { actions }}+\frac{\sum \text { action } 9}{\sum \text { actions }}
$$

$\Sigma$ action $1=$ Welding;

$\Sigma$ action 2 = Collecting cables, removing PPE's and storing;

$\Sigma$ action 3 = Cleaning and storing the work area;

$\Sigma$ action $4=$ Closing spool openings to purge;

$\Sigma$ action $5=$ Making the change of diffuser and/or torch nozzle and/or sharpening the tungsten;

$\Sigma$ action 6 = Sanding;

$\Sigma$ action $7=$ Evaluating the task (position, questions with supervisor);

$\Sigma$ action $8=$ Spool adjustments and alignments;

$\Sigma$ action $9=$ Recording the signet;

$\Sigma$ actions $=3577$, total of observations.

The Idleness Rating Factor function obtained through Monte Carlo simulation, which is the sum of the functions related to the Non-productive category, according to the following Equation 4, gave rise to the Density Curve presented in Figure $1 \mathrm{~b}$. The average Probability Distribution Function result is 0.4549 with Standard deviation of 0.1035 maximum of 0.9692 minimum of 0.1785 and coefficient of variation of 0.2275 .

$$
\mathrm{IRF}=\frac{\Sigma \text { action } 10}{\Sigma \text { actions }}+\frac{\Sigma \text { action } 11}{\Sigma \text { actions }}+\frac{\Sigma \text { action } 12}{\Sigma \text { actions }}+\frac{\Sigma \text { action } 13}{\Sigma \text { actions }}+\frac{\Sigma \text { action } 14}{\Sigma \text { actions }}+\frac{\Sigma \text { action } 15}{\Sigma \text { actions }}+\frac{\Sigma \text { action } 16}{\Sigma \text { actions }}+\frac{\Sigma \text { action } 17}{\Sigma \text { actions }}
$$

At where:

$\Sigma$ action $10=$ Displacements;

$\Sigma$ action $11=$ No joints released to start welding;

$\Sigma$ action 12 = Interruption of activities due to the movement of loads near the workbench;

$\Sigma$ action 13 = Waiting for crane availability;

$\Sigma$ action $14=$ Waiting for the arrival of the inspector to the joint release;

$\Sigma$ action 15 = Human Conditions - Interaction with colleagues, cool the body, drink water and go to the bathroom;

$\Sigma$ action 16 = Safety and Management Meetings;

$\Sigma$ action $17=$ No welding machine or defective machine;

$\Sigma$ actions $=3577$, total of observations. 

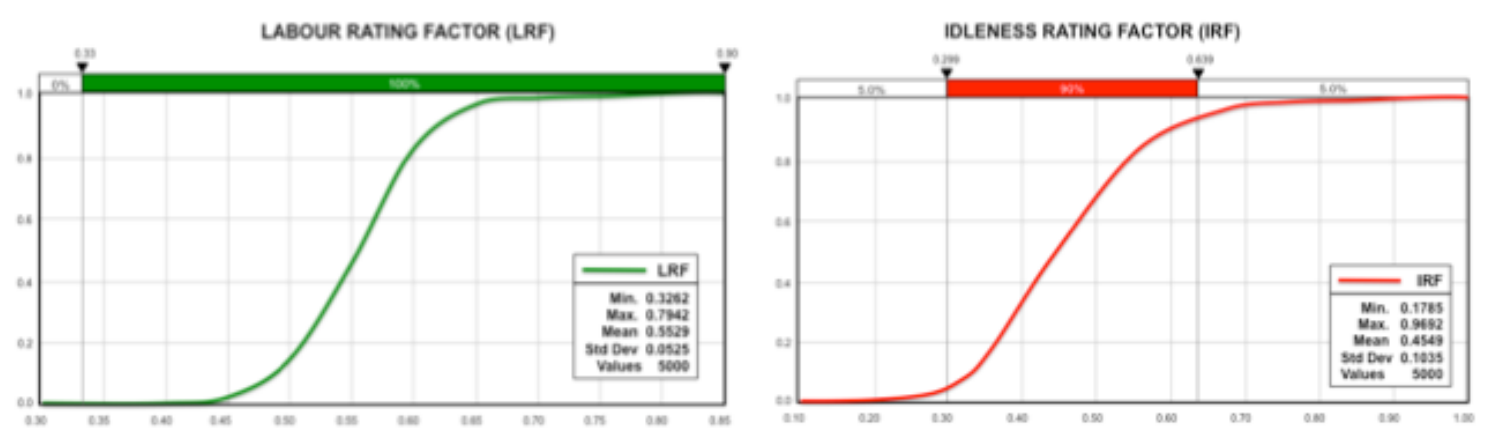

Figure 1: Density curve, a. Labour Rating Factor; b. Idleness Rating Factor

\subsection{Validation of the modelling by work sampling analysis}

According to Adrian (2004), the proportions of the productive and non-productive categories are determined by the ratio of the sum of all observations in both categories and the total number of observations recorded. Thus, in relation to the total sample of 3577 observations, of which 1986 were identified as productive and 1591 nonproductive, the values of 0.5552 Labour Rating Factor and 0.4448 for the Idleness Rating Factor were determined. Also according to Adrian (2004), it is possible to measure the percentage error limit relative to the sample size in the considered confidence interval. In this work, a 0.0241 error was determined for a sample composed by 3577 observations, within a 0.9500 confidence limit, for the 0.5000 proportion category, and the calculation of this value was based on the interpolation of the values of Table 1 , shown above. In this sense, considering this error, the Labour Rating Factor is between 0.5311 and 0.5793 . Determining the Labour Rating Factor via Monte Carlo simulation yields the mean value of 0.5530 , with the standard deviation of this Probability Distribution Function being 0.0525 . Thus, for this Probability Distribution Function, the coefficient of variation is 0.0950 . In this sense, it can be inferred that the Labour Rating Factor determined in this way is between 0.5005 and 0.6055 .

It should be noted that the variability experienced by the average Labour Rating Factor determined by Monte Carlo simulation was expected because the curve representing this function is the result of the sum of the random variables that compose it, in which each have an associated dispersion. In this way, the sum of the dispersions of each of the curves will have an impact on the dispersion of the Probability Distribution Function resulting from the sum of them. However, the values obtained by the Monte Carlo simulation compared to those determined through the sampling chart are very similar, which allows affirming that the Probability Distribution Function obtained by this technique adequately represents the behaviour of the Occupancy Factor. In view of this observation, it can be stated that the method of observation used in this work is feasible and can be employed by obtaining results with reasonable accuracy. On the other hand, considering that the model used in performing the Monte Carlo simulation has shown to be adequate, it is possible, through the use of the sensitivity analysis technique, to evaluate the impact of each variable on the Labour Rating Factor.

Analogously to the Labour Rating Factor, the Idleness Rating Factor determined by the sampling letter is 0.4448 . Considering the error of 0.0241 for a 0.9500 confidence interval, the Idleness Rating Factor is between 0.4207 and 0.4689 . The Probability Distribution Function obtained through Monte Carlo simulation presented the mean value of 0.4549 , standard deviation of 0.1035 and dispersion coefficient of 0.2275 . In 
this case, it is verified that the average of the Idleness Rating Factor is between 0.3514 and maximum with 0.5584 .

The higher dispersion observed in the Probability Distribution Function of the Idleness Rating Factor compared to the Labour Rating Factor can be explained by the fact that the variables that make up this model are much more difficult to model. On the other hand, in this study were grouped events with different characteristics in the same variable, which may have contributed to increase the dispersion. In this way, the impact on the Probability Distribution Function dispersion of the Idleness Rating obtained through the Monte Carlo simulation will be higher than that observed in the Labour Rating. Although, in this case, the methodology used to determine the Idleness Rating is adequate. However, it is possible to reduce the dispersion in these cases by improving the modelling of each activity and increasing the number of observations made.

\subsection{Diagnostic of impact factors by sensitivity analysis}

The sensitivity analysis by the Tornado graph (Figure 2), shows the influence of the variables on the average of the Labour Rating Factor. Each impact factor is evaluated within an upper and lower limit in the surroundings of the mean, so, according to the classification, the simulated values presented in the dark green bars indicate a high input, in this way 7 variables were diagnosed in this category. Light green bars indicate low input - 11 variables have been diagnosed in this category. It can be observed that the activities of collecting cables, removing PPE's and storing equipment and cleaning the work area are of low impact on the average of the Labour Rating Factor. On the other hand, the welding activity presents the greatest impact, exceeding the inherent dispersion of the process of 0.0950 around the mean. The other activity with the highest impact on the average of the Labour Rating Factor is Sanding. This result was expected given that these are the main activities of welders, as they make up the executive welding procedure. In order to apply improvement actions in the activities observed in order to increase the average value of the Labour Rating Factor, it is necessary to prioritize activities with high input and that exceed the dispersion of the mathematical model, after which one must act in the determined activities as high input, and lastly, there is no indication of high effort improvements in activities characterized only by low input.

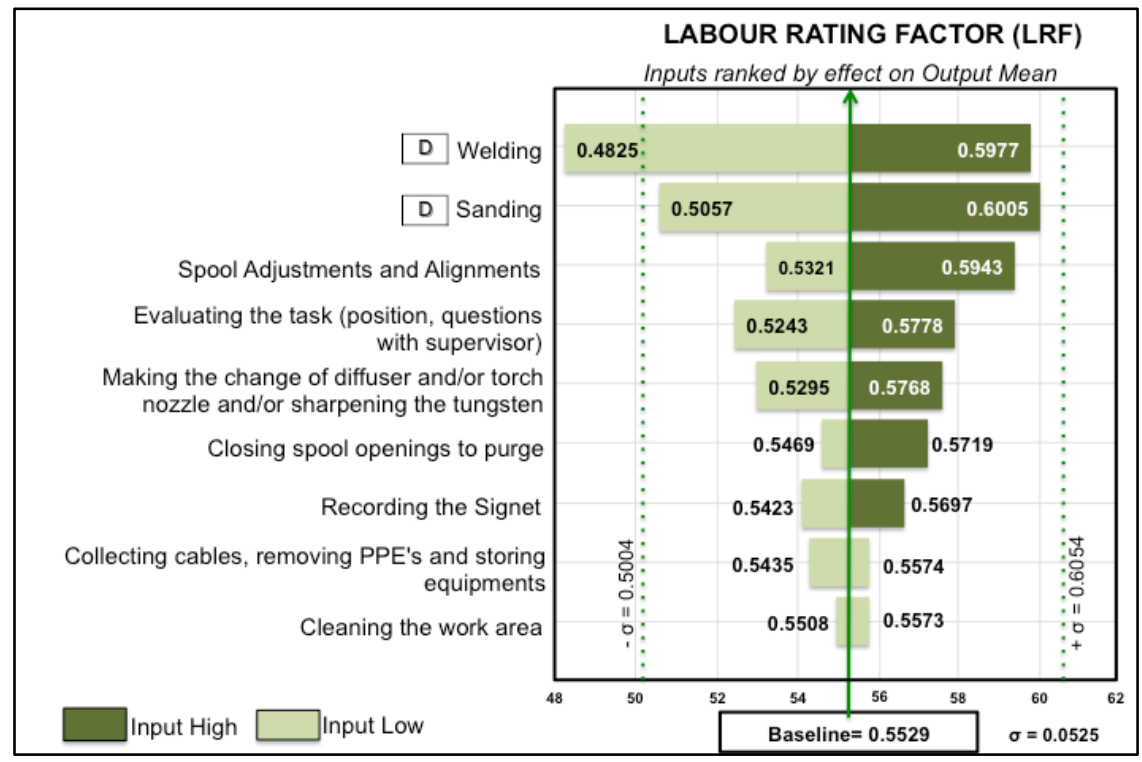

Figure 2: Tornado chart, impact factor on LRF 
The activities that are called direct, that is, those that concern the effective production process, are: welding and sanding. The other activities are considered indirect or supportive. The determinant variables of the Labour Rating Factor, which are equalized in a proportional way in Table 3, with the proportional relative to the Productive State (Productive + Non-productive), indicate that the welding actions and sanding correspond to 0.4193 of the time worked welders. Regarding the classification of the state of production, based on Adrian (2004), it can be observed that the occupation time of the welders is distributed in 0.7553 for activities directly related to the welding process and in 0.2447 for support activities or auxiliaries.

\begin{tabular}{|c|c|c|c|}
\hline $\begin{array}{l}\text { Productive } \\
\text { State }\end{array}$ & ID & Identified Actions & Proportion \\
\hline \multirow{9}{*}{ Productive } & 1 & Welding & 0,2991 \\
\hline & 2 & Collecting cables, removing PPE's and storing equipments & 0,1202 \\
\hline & 3 & Cleaning the work area & 0,0458 \\
\hline & 4 & Closing spool openings to purge & 0,0319 \\
\hline & 5 & $\begin{array}{l}\text { Making the change of diffuser and/or torch nozzle and/or sharpening the } \\
\text { tungsten }\end{array}$ & 0,0210 \\
\hline & 6 & Sanding & 0,0196 \\
\hline & 7 & Evaluating the task (position, questions with supervisor) & 0,0089 \\
\hline & 8 & Spool Adjustments and Alignments & 0,0067 \\
\hline & 9 & Recording the Signet & 0,0020 \\
\hline
\end{tabular}

Table 3: Proportion, variables of the productive state

Similarly, the sensitivity analysis by the Tornado graph (Figure 3), shows the influence of the variables on the average of the Idleness Rating Factor. However, it should be noted that the dispersion in this case is much higher than that obtained in the Labour Rating Factor. In this way, when carrying out the sensitivity analysis, the impact of each of the variables should be seen as a qualitative indication of the importance of the same in the formation of the Idleness Rating Factor. Considering these caveats, each impact factor is evaluated within an upper and lower limit in the surroundings of the mean, so, according to the classification, the simulated values presented in the dark red tone bars indicate a high input, being diagnosed 6 variables in this category, because the bars in light red indicate low input, in which 10 have been diagnosed in this category. It can be observed that the activities of safety and management meetings and interruption of activities due to the movement of loads near the workbench had the least impact on the Idleness Rating Factor. On the other hand, displacements and human conditions activities have the greatest impact on the Idleness Rating Factor and should be prioritized in the application of improvement actions. 


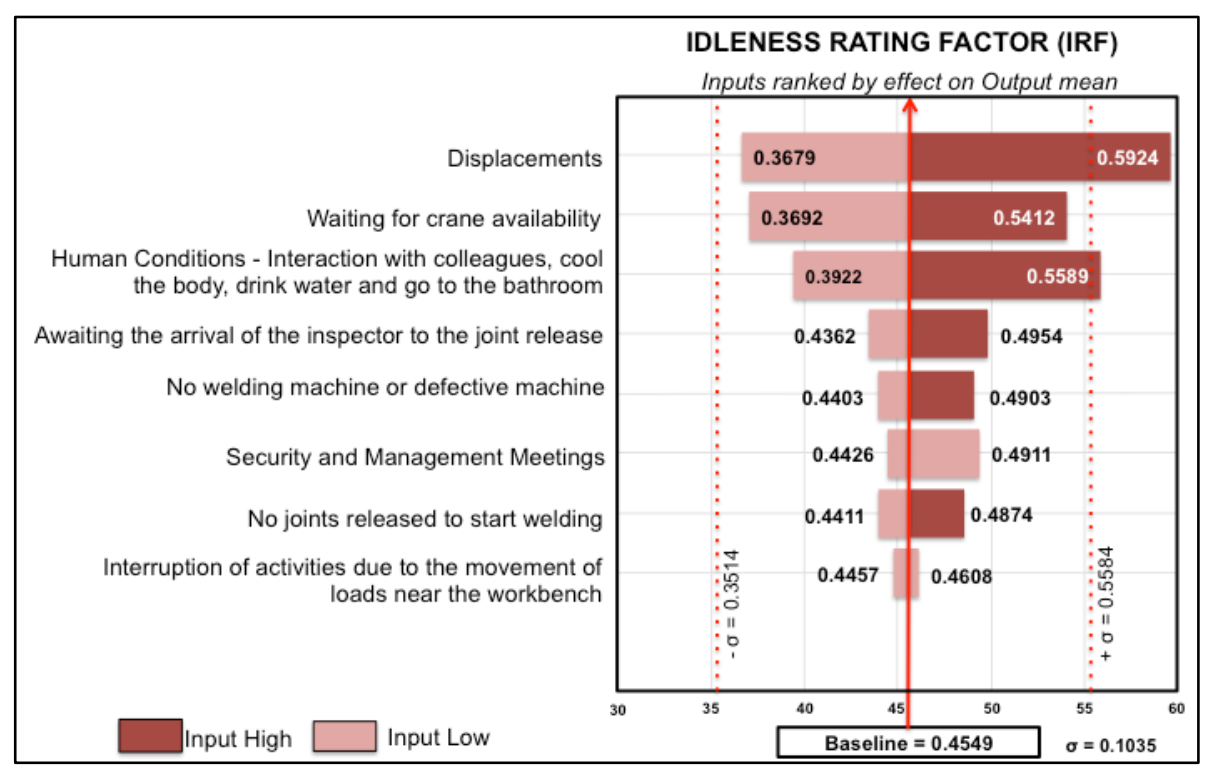

Figure 3: Tornado chart, impact factors on IRF

The determinant variables of the Idleness Rating Factor are organized and presented in a proportional way in Table 4, with weight relative to the Productive State (Productive + Non-productive), demonstrating that the activities Displacements, Human Conditions, Waiting for crane availability and Security and Management Meetings, jointly consume 0.3897 of the workday time of welders.

\begin{tabular}{|c|c|c|c|}
\hline $\begin{array}{l}\text { Productive } \\
\text { State }\end{array}$ & ID & Identified Actions & Proportion \\
\hline \multirow{8}{*}{ Nonproductive } & 10 & Displacements & 0,1862 \\
\hline & 11 & No joints released to start welding & 0,0942 \\
\hline & 12 & $\begin{array}{l}\text { Interruption of activities due to the movement of loads near } \\
\text { the workbench }\end{array}$ & 0,0668 \\
\hline & 13 & Waiting for crane availability & 0,0425 \\
\hline & 14 & Awaiting the arrival of the inspector to the joint release & 0,0226 \\
\hline & 15 & $\begin{array}{l}\text { Human Conditions - Interaction with colleagues, cool the } \\
\text { body, drink water and go to the bathroom }\end{array}$ & 0,0148 \\
\hline & 16 & Security and Management Meetings & 0,0143 \\
\hline & 17 & No welding machine or defective machine & 0,0034 \\
\hline
\end{tabular}

Table 4: Proportion, variables of the non-productive state

According to Adrian (2004), in a construction site in the United States, an average of 0.1500 of the working time is consumed, as result of the needs inherent to the Human Conditions, being able to reach up to 0.2000 of the daily occupation. In this sense, the value established in the study for the variable Human Conditions, which include Interaction among colleagues, cooling of the body, drinking water and using the restrooms is 0.0942 . This minor unproductiveness in this item, can be explained by the fact that the study was conducted in a factory, where the distances travelled to drink water and to use the restrooms are smaller than those at a construction site and closer to the front of service. On the other hand, in a similar study carried out by Souza (2015), the percentage of time consumed by this variable is 0.1460 . During the experiment, it was observed the unavailability of one of the two cranes of the shed, which resulted in the need for additional waiting for the withdrawal of the finished spool and in the increase of the time of placement of new element for welding in front of service of each welder. According to Adrian (2004), the impacts due to the excessive delay in the 
beginning and end of the tasks impact 0.0600 of the working time, which can be related to the value of 0.0668 related to the availability of the crane, and Souza (2015) identified an index of 0.0900 .

According to Adrian (2004), 0.1600 of the working time is impacted due to waiting times between factors such as materials, equipment and other employees, and 0.0700 due to lack of optimization of the layout of service fronts. It was observed in the study that the displacements are directly related to the mobility of the welders to obtain materials and work equipment, as well as identifying the long distance of the allocation of these resources the service fronts. Also, the impact of the activity waiting, performed by other professionals such as inspection for quality control and coupling was identified, as well as defective equipment and interruptions due to cargo handling activities. Thus, considering these factors as Waiting for other factors and the Layout of the factory, the value reached is 0.2413 , and, in this case, it can be compared to the 0.2300 reported by Adrian (2004). Souza (2015) identified that the lack of Material, Adjustments in Welding Equipment and Inspection for Quality Control together consumed 0.1240 of the total time of the working day. Finally, it was not possible to identify analogies to the time spent with Security and Management Meetings, which are pertinent to the times observed in Security Dialogues, Meetings with the Supervision and Evaluation of Welding Requirements in Management, which totalled 0.0425 of the welders' journey. A comparison of the results obtained in this study, and those presented by Adrian (2004) and Souza (2015), is presented in Figure 4.

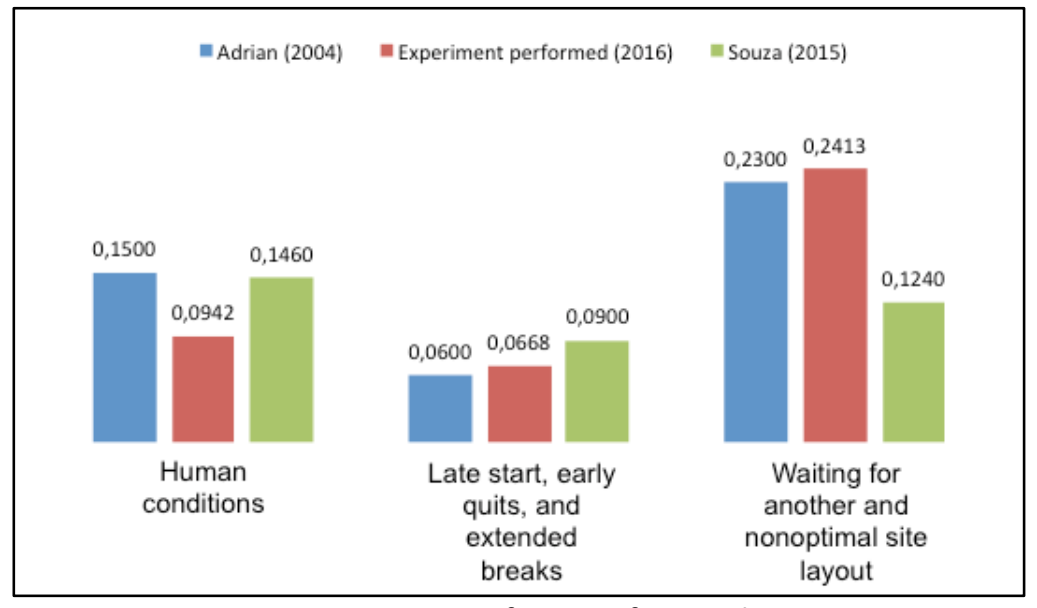

Figure 4: Comparative factors of unproductivity

\section{Conclusions}

The agile methodology of data collection and treatment applied, allows the precise identification of the actions performed by the workers. Where the recording of the Productive or Non-productive state is carried out only by means of occasional notes, without the need to use timing. In this way, it has proved to be an effective and simplified tool, allowing the registration of the degree of participation of all the events that make up the Labour and Idleness Rating Factors. The records obtained and processed through Monte Carlo simulation allowed the evaluation of the relevance of each event involved in the process. Also, the comparison of the average Probability Distribution Function of the Labour Rating Factor and Idleness Rating Factor curves obtained through Monte Carlo simulation, with the results obtained through work sampling analysis, demonstrate the reliability of the methodology. 
The use of Sensitivity Analysis enabled the evaluation and classification of the impact of each event that make up the Labour Rating Factor and Idleness Rating Factor. Based on this, it is possible to prioritize and apply corrective actions that allow continuous improvement during the production process.

The dispersion observed in the Function of the Idleness Rating Factor was greater than the Function of the Labour Rating Factor. This fact can be explained by the fact that the events that compose the Idleness Rating Factor are more difficult to model than the activities that make up the Labour Rating Factor. In the same way, in this work were grouped, in the same variable, events with different characteristics that compose the Idleness Rating Factor. Improving the modelling of these events and increasing the number of observations may improve the accuracy achieved in this work. Thus, in this article, the quantification of the impact of the variables that compose the Labour Rating Factor has a higher degree of reliability than in the case of the Idleness Rating Factor. That should be considered in the performance of the Sensitivity Analysis to evaluate the impact of the same in the two developed curves.

The analysis of the behaviour of the Labour Rating Factor reveals that 0.7553 of the welders' productive time in labour activities is consumed in the activities directly related to the welding process and 0.2447 are related to support or auxiliary activities. This result is an additional benefit of the agile methodology, since it allows the manager to decide on the accomplishment of actions that optimize the use of the labour force in the execution of the main activities.

\section{References}

Abdel-Razek, R. H., H. Abd Elshakour M, and M. Abdel-Hamid. 2007. "Labor productivity: Benchmarking and variability in Egyptian projects". International Journal of Project $\begin{array}{lllll}\text { Management 25, no. } & 2 & \text { (february): }\end{array}$ https://doi.org/10.1016/j.ijproman.2006.06.001.

Adrian, James J. 2004. Construction productivity: Measurement and improvement. Champaign. IL: Stipes Publishing.

Allmon, Eric, Carl T. Haas, John D. Borcherding, and Paul M. Goodrum. 2000. "U.S. construction labor productivity trends, 1970-1998". Journal of Construction Engineering and Management 126, no. 2 (march): 97-104. https://doi.org/10.1061/(ASCE)0733-9364(2000)126:2(97).

Alvanchi, Amin, SangHyun Lee, and Simaan AbouRizk. 2012. "Dynamics of working hours in construction". Journal of Construction Engineering and Management 138, no. 1 (january): 66-77. https://doi.org/10.1061/(ASCE)CO.1943-7862.0000384.

Chan, Wai Kin Victor, and Charles J. Malmborg. 2013. "On the effectiveness of Monte Carlo simulation and heuristic search for solving large-scale block layout problems". International Journal of Production Research 51, no. 14 (march): 4258-72. https://doi.org/10.1080/00207543.2012.762129.

Choudhry, Rafiq M., Mohammad A. Aslam, Jimmie W. Hinze, and Faisal M. Arain. 2014. "Cost and schedule risk analysis of bridge construction in Pakistan: Establishing risk guidelines". Journal of Construction Engineering and Management 140, no. 7 (july): 04014020. https://doi.org/10.1061/(ASCE)CO.1943-7862.0000857.

Christian, John, and Daniel Hachey. 1995. "Effects of delay times on production rates in construction". Journal of Construction Engineering and Management 121, no. 1 (march): 20-26. https://doi.org/10.1061/(ASCE)0733-9364(1995)121:1(20). 
Constâncio, D. S., M. L. R. Ferreira, and I. J. Freire. 2009. "Estimativa de produtividade na soldagem de tubulações industriais utilizando o método de Monte Carlo". Paper presented at XXXV CONSOLDA - Congresso Nacional de Soldagem, Piracicaba, São Paulo, Brasil, October 26-29, 2009.

Czumanski, Thomas, and Hermann Lödding. 2016. "State-based analysis of labour productivity". International Journal of Production Research 54, no. 10 (june): 293450. https://doi.org/10.1080/00207543.2015.1137372.

Doloi, Hemanta, Anil Sawhney, K. C. Iyer, and Sameer Rentala. 2012. "Analysing factors affecting delays in Indian construction projects". International Journal of Project $\begin{array}{lllll}\text { Management } 30, & \text { no. } & 479-89 .\end{array}$ https://doi.org/10.1016/j.ijproman.2011.10.004.

Enshassi, Adnan, Sherif Mohamed, Peter Mayer, and Karem Abed. 2007. "Benchmarking masonry labor productivity". International Journal of Productivity and Performance Management 56, no. 4: 358-68. https://doi.org/10.1108/17410400710745342.

Flanagan, Roger, and George Norman. 1993. Risk management and construction. Oxford: Blackell Science.

Gelisen, Gokhan, and F. H. Griffis. 2014. "Automated productivity-based schedule animation: Simulation-based approach to time-cost trade-off analysis". Journal of Construction Engineering and Management 140, no. 4: B4013007. https://doi.org/10.1061/(ASCE)C0.1943-7862.0000674.

Jovanović, Petar. 1999. "Application of sensitivity analysis in investment project evaluation under uncertainty and risk". International Journal of Project Management 17, no. 4 (august): 217-22. https://doi.org/10.1016/S0263-7863(98)00035-0.

Lobato, Marcos Müller. 2015. "Utilização de misturas com argônio e CO2 na soldagem de arames tubulares em aço carbono ASTM A36". Master's thesis, Mestrado Profissional em Montagem Industrial, Universidade Federal Fluminense.

Martins, José L. F., Miguel L. R. Ferreira, Juan M. Pardal, and Cássia A. R. Morano. 2012. "Comparación de la estimación de la productividad del proceso de soldadura eléctrica por los métodos de simulación de Monte Carlo e Hipercubo Latino". Información tecnológica 23, no. 4: 21-32. http://dx.doi.org/10.4067/S0718-07642012000400004.

Martins, José Luiz Ferreira, Miguel Luiz Ribeiro Ferreira, and José Murilo Ferraz Saraiva. 2011. "Estimativa da produtividade em soldagem pelo Método de Monte Carlo Productivity estimation in welding by Monte Carlo Method". Soldagem \& Inspeção 16, no. 3: 204-12. http://dx.doi.org/10.1590/S0104-92242011000300002.

Mojahed, Shahriyar, and Fereydoun Aghazadeh. 2008. "Major factors influencing productivity of water and wastewater treatment plant construction: Evidence from the deep south USA". International Journal of Project Management 26, no. 2 (february): 195-202. https://doi.org/10.1016/j.ijproman.2007.06.003.

Nasirzadeh, Farnad, and Pouya Nojedehi. 2013. "Dynamic modeling of labor productivity in construction projects". International Journal of Project Management 31, no. 6 (august): 903-11. https://doi.org/10.1016/j.ijproman.2012.11.003.

Navon, Ronie. 2005. "Automated project performance control of construction projects". Automation in Construction 14, no. 4 (august): 467-76. https://doi.org/10.1016/j.autcon.2004.09.006. 
Park, Hee-Sung, R. Thomas Stephen, and L. Tucker Richard. 2005. "Benchmarking of Construction Productivity". Journal of Construction Engineering and Management 131, no. 7: 772-78. https://doi.org/10.1061/(ASCE)0733-9364(2005)131:7(772).

Pradhan, Anu, Burcu Akinci, and Carl T. Haas. 2011. "Formalisms for query capture and data source identification to support data fusion for construction productivity monitoring". Automation in Construction 20, no. 4 (july): 389-98. https://doi.org/10.1016/j.autcon.2010.11.009.

Raftery, John. 2003. Risk analysis in project management. Routledge.

Schuyler, John R. 2001. Risk and decision analysis in projects. Project Management Institute.

Song, Lingguang, and Simaan M. AbouRizk. 2008. "Measuring and modeling labor productivity using historical data". Journal of Construction Engineering and Management 134, no. 10 (october): 786-94. https://doi.org/10.1061/(ASCE)07339364(2008)134:10(786).

Souza, Ricardo Felício. 2015. "Monitoração da produtividade em soldagem de tubulações industriais de aço carbono". Especialização em Montagem Industrial e Fabricação Mecânica, Universidade Federal Fluminense.

Thomas, H. Randolph, and Ivica Završki. 1999. "Construction baseline productivity: Theory and practice". Journal of Construction Engineering and Management 125, no. 5 (september): 295-303. https://doi.org/10.1061/(ASCE)07339364(1999)125:5(295).

Yi, Wen, and Albert P. C. Chan. 2013. "Optimizing work-rest schedule for construction rebar workers in hot and humid environment". Building and Environment 61, (march): 104-13. https://doi.org/10.1016/j.buildenv.2012.12.012. 